\title{
BEADS OF THE BIRSK BURIAL GROUND IN THE CONTEXT OF THE ANTIQUITIES OF THE EARLY MIDDLE AGES
}

\author{
Rida Raisovna Ruslanova \\ Researcher, Training and Research Archaeological Laboratory, \\ Bashkir State University \\ ridushka@mail.ru \\ Zaki Validi St., 32, 450076 Ufa, Russian Federation
}

\begin{abstract}
Early Middle Ages in the Southern Urals is the time of the tumultuous ethnocultural processes, that is an echo of the era of the Great Migration. At this time, the bakhmutinskaya culture was formed (3rd-8th centuries A.D.). The Birsk burial ground is one of the unique monuments of this period - it appeared in the second third of the 1st millennium B.C. The Birsk burial ground is a fiducial monument for studying history, ethno-cultural, migration and trade processes occurring in the Southern Urals, and the content in the composition of grave goods makes it supplies an important source in the study of early medieval history of East European forest. A variety of types of beads from the Birsk burial ground allows suggesting that the necropolis was one of the major points on the caravan trade and exchange path. According to it, the exchange could take place on imports of products (furs, honey, metals).

The article describes a set of beads from the Birsk burials - evidence of a monument in the system of early medieval antiquities (3rd-8th centuries A.D.). The complex morpho-technological research dealt with 218 complexes containing 6705 instances of beads and jewelry. The feature of the monument is the presence of necklaces jewelry from all the selected materials along with the material. The Birsk burial ground demonstrates various forms of products, colors used glass for monochrome and polychrome decorations. The presented work can be used in the study of material culture and trade exchange operations of the medieval population of the Urals.
\end{abstract}

Key words: middle ages, beads, Southern Urals, Birsk burial ground, Ufa-II hillfort, trade, trade routes.

УДК 902/904

Дата поступления статьи: 15.12.2015

ББК 63.4

\section{БУСИННЫЕ УКРАШЕНИЯ БИРСКОГО МОГИЛЬНИКА В КОНТЕКСТЕ ДРЕВНОСТЕЙ ЭПОХИ РАННЕГО СРЕДНЕВЕКОВЬЯ}

\section{Рида Раисовна Русланова}

Научный сотрудник учебно-научной археологической лаборатории, Башкирский государственный университет ridushka@mail.ru ул. Заки Валиди, 32, 450076 г. Уфа, Российская Федерация

Аннотация. В работе рассмотрена бусинная коллекция Бирского могильника - реперного памятника в системе древностей эпохи раннего Средневековья (III-VIII вв. н. э.). Комплексным морфо-технологическим $\stackrel{\circ}{\circ}$ иссли бованием было изучено 218 комплексов, содержащих 6705 экз. бусинных украшений. Особенностью памятника является наличие в составе ожерелий бус из всех материалов, выделенных для бусинных украшений Южного Приуралья. Бирский могильник демонстрирует разнообразие представленных форм изделий, цветов используемого стекла для монохромных и полихромных украшений. Представленная работа может быть использована при исследовании материальной культуры и торгово-обменных операций средневекового населения Приуралья, установлении хронологии и датировки древностей I тыс. н. э.

Ключевые слова: Средневековье, бусы, Южное Приуралье, Бирский могильник, городище Уфа-II, торговля, торговые пути. 
Раннее Средневековье на Южном Урале - время бурных этнокультурных процессов, являвшихся отголоском эпохи Великого переселения народов. В это время здесь на основе местных кара-абызских племен эпохи раннего железного века сформировалась бахмутинская культура (III-VIII вв.), которая впоследствии испытала на себе влияние пришлых групп турбаслинского и кушнаренковско-караякуповского населения. Результатом стало изменение этнического состава региона. В это время исчезают ранние грунтовые могильники (Ангасякский, Югомашевский, Малокачакский) и появляются новые - курганные (Турбаслинский, Дежневский, Шареевский). Одним из уникальных памятников этого времени является Бирский грунтовый могильник он функционирует на всем протяжении второй трети I тысячелетия н. э.

Памятник площадью более 30000 кв. м расположен на одном из мысов р. Белой. Открытый в 1902 г., он неоднократно привлекал внимание исследователей. Так, планомерные полевые раскопки были проведены в 19591960, 1962, 1978, 1981-1991 гг. Н.А. Мажитовым. За эти годы было вскрыто 692 погребения, разнообразный материал которых является неотъемлемой частью большинства исследований по хронологии, оружиеведению, хозяйству раннего средневековья всего Евразийского пространства $[1 ; 2 ; 5$ и др.].

Конструктивные особенности могил, антропологический материал, элементы поясной гарнитуры, украшения позволили Н.А. Мажитову выделить и датировать участки заполнения площадки памятника (II-IV вв., IVV вв., V-VI вв., VI-VII вв.) и отнести комплекс находок к предметам бахмутинской, турбаслинской, кушнаренковской и караякуповской культур [3, табл. 1]. В дальнейшем хронологические рамки памятника были несколько скорректированы в пределах III-VIII вв. н. э. Определено, что некрополь генетически восходит к культуре автохтонного (пьяноборского и кара-абызского) населения эпохи раннего железного века, с определенным влиянием культуры кочевников южно-уральской лесостепи [10].

Бирский могильник - реперный памятник для исследования хронологии, этнокультурных, миграционных, торгово-обменных про- цессов, протекавших на Южном Урале, а содержание в составе погребального инвентаря привозных изделий делает его материалы немаловажными источниками при изучении раннесредневековой истории восточноевропейской лесостепи. К таким находкам принадлежит наиболее массовая категория находок в захоронениях Бирского могильника - бусы. Многочисленные аналогии с бусинными украшениями традиционных регионов стеклоделия и отсутствие каких-либо следов стеклодельных и камнерезных мастерских на Южном Урале и прилегающих территориях в эпоху раннего средневековья позволяют без сомнения отнести бусы к числу предметов так называемого «дальнего импорта».

Научная емкость данного вида находок глубока: бусы, являясь чутким хронологическим индикатором, позволяют выйти на проблемы датирования археологических комплексов, определения направлений и характера контактов населения, установления ареалов распространения бус, выявления отличительных особенностей отдельных групп населения. Не стали исключением и бусы Бирского могильника. Отдельные бусинные коллекции в составе всего комплекса погребального инвентаря ранее уже были включены исследователями в общие работы по археологии Приуралья середины I тыс. н. э.

Впервые бусинные украшения Бирского могильника использованы в качестве хрономаркеров в работе Н.А. Мажитова [3]. При выделении раннего и позднего этапов в развитии бахмутинской культуры была отмечена своя специфика в наборах бус каждого периода. Используя в комплексе погребального инвентаря мазунинской культуры (исследования уральских археологов последних лет позволяют соотнести мазунино с ранним периодом бахмутинской культуры) украшения Бирского могильника, Т.И. Останина выделила хронологические группы бус и отметила запаздывание их поступления в Приуралье [5]. Однако как самостоятельный предмет исследования бусы были использованы намного позже при проведении морфологического анализа части коллекций некрополя [12]. Морфотехнологическое описание, систематика, выделение хронологических групп, определение вероятных центров производств и путей по- 
ступления бус было осуществлено автором статьи в процессе изучения состава бусинных коллекций средневековых некрополей Уфимско-Бельского междуречья, когда были исследованы бусы 12 некрополей общим числом 36770 экз. [6; 7]. В Бирском могильнике изучена выборка из 218 погребений, содержащая 6705 экз. бусинных украшений.

В отличие от коллекций Югомашевского могильника (бахмутинская культура, III-V вв.), где в захоронениях встречено до 2000 бусин [8], погребения Бирска включали небольшое число бус: в 42 погребениях (20\%) найдено по 1 бусине, в 118 могилах (56 \%) содержатся от 2 до 20 экз. бус. Максимальное количество бус в одном погребении достигает 732 экземпляров.

Еще одной отличительной особенностью могильника может считаться наличие и превалирование бус из стекла (5 785 экз., 87 \%), раковины Turbo marmoratus (807 экз., $12 \%$ ). В погребениях Бирского могильника найдено большинство янтарных, коралловых и сердоликовых украшений (83 экз., 1 \%, 171 экз., 25 экз. соответственно), встречена единственная хрустальная бусина. Только в погребениях этого могильника обнаружены 2 бусины из «египетского фаянса». Еще одной особенностью тафокомплекса, является включение в состав элементов декора костюмного комплекса раковин каури (Cypraeidae).

Бирский могильник демонстрирует также разнообразие форм изделий - среди стеклянных бус выделено 18 форм, из которых 5 форм встречены только в данном некрополе. Только в Бирском могильнике найдено наибольшее количество округлых (зонных, шаровидных, биконических и пр.) и плоскогранных форм (полиэдрические бусы). В некрополе найдены ребристые (в том числе из египетского фаянса) и фигурные бусы. Форма изделий из янтаря и камней-самоцветов также различна. В Бирском могильнике бусы из раковин моллюсков представлены 10 формами. В состав ожерелий население, оставившее некрополь, включало круглые и треугольные подвески, раковины каури. Многообразие форм раковинных бус дает возможность выдвинуть предположение о наличии у местного населения собственных мастерских по вытачиванию бус из привозных раковин.
Могильник выделяется среди прочих синхронных погребальных памятников региона, в том числе и цветовой палитрой представленных бус (выделено 14 цветов). В нем встречены монохромные (5 422 экз., 94 \%) - наибольший процент среди них составляют синие и желтые бусы (2 575 и 1239 экз. соответственно), красных, зеленых и бирюзовых бус меньше. Население, оставившее могильник, включало в состав ожерелий бусины с металлической (золотой и серебряной) фольгой (299 экз., 5 \%) и декорированные (64 экз., 1 \%) бусы. Среди преобладающего количества глазчатых, глазчато-ресничных, поперечнополосатых бус (16, 10 и 10 экз. соответственно) выделяется бусина с узором в виде розетки - цветка.

Технология изготовления стеклянных украшений также весьма различна: деление тянутой трубочки (5 171 экз., $89 \%$ ), деление тянутой палочки (395 экз., 7 \%), навивка (146 экз., 3 \%), сгиб полосы/палочки (69 экз., $1 \%$ ), сварка (4 экз., менее $1 \%$ ).

Бирский могильник содержит уникальные для южноуральского региона находки (элементы поясной гарнитуры, монеты Сафшафана [4], стеклянный кубок [3], фигурку всадника [11]), что может указывать на его значимость и важную роль оставившего его населения в эпоху раннего средневековья на всей территории Бельско-У фимского междуречья. Бусы, являясь массовым материалом в погребениях III-VIII вв., в Бирском некрополе проявляют свою особенность - на основе комплексного анализа только здесь обнаружено 89 типов бус, нигде более не встречавшихся (общая систематика бусинной коллекции 12 некрополей Уфимско-Бельского междуречья III-VIII вв. состоит из 259 типов и подтипов, включающих 36770 экз. бус). Только в погребениях этого некрополя найдены фаянсовые, крупные янтарные бусы и единственный экземпляр бусины из хрусталя.

Количественные, морфо-технологические показатели и разнообразие типов бус в Бирском могильнике позволяют выдвинуть предположение о том, что территория расселения людей, оставивших некрополь, наряду с городищем Уфа-ІІ являлась одним из крупных (конечных?) пунктов прибытия караванов, продвигающихся Бельским торгово-обменным путем [9; 13]. По 
нему мог проходить обмен импорта на продукцию приуральского лесостепного и лесного населения (пушнина, мед, металлы).

\section{СПИСОК ЛИТЕРАТУРЫ}

1. Амброз, А. К. Бирский могильник и проблемы хронологии Приуралья в IV-VII вв. / А. К. Амброз // Средневековые древности евразийских степей. -M. : Наука, 1980. - С. 1-56.

2. Ковалевская, В. Б. Башкирия и евразийские степи IV-IX вв. (по материалам поясных наборов) / В. Б. Ковалевская // Проблемы археологии и древней истории угров. - М. : Наука, 1972. C. $95-118$.

3. Мажитов, Н. А. Бахмутинская культура / Н. А. Мажитов. - М. : Наука, 1968. - 161 с.

4. Мажитов, Н. А. Комплексы с монетами VIII в. из Бирского могильника / Н. А. Мажитов // Советская археология. - 1990. - № 1.-С. 261-266.

5. Останина, Т. И. Население Среднего Прикамья в III-V вв. / Т. И. Останина. -Ижевск : Удмуртский институт истории, языка и литературы УрО PAH, 1997. - $327 \mathrm{c}$.

6. Русланова (Тамимдарова), Р. Р. Бусы-хрономаркеры могильников Уфимско-Бельского междуречья III-VIII вв. / Р. Р. Русланова (Тамимдарова) // Вестник Самарского государственного университета. - № 8/1 (109). - С. 170-174.

7. Русланова, Р. Р. Классификация бус раннесредневековых могильников Южного Приуралья / Р. Р. Русланова // Труды IV (XX) Всероссийского археологического съезда в Казани. - Казань : Отечество, 2014. - Т. II. - С. 403-405.

8. Русланова (Тамимдарова), Р. Р. Особенность бусинных наборов Югомашевского могильника / Р. Р. Русланова (Тамимдарова) // Инновационный потенциал молодежной науки : материалы Bcерос. науч. конф. (8 нояб. 2013 г.). - Уфа : Изд-во БГПУ, 2013. - С. 236-240.

9. Русланова, Р. Р. Пути и характер взаимодействия населения лесостепного Приуралья в эпоху раннего средневековья (по материалам бус Уфимско-Бельского междуречья) / Р. Р. Русланова // Этносы и культуры Урало-Поволжья: история и современность : материалы VIII Bсерос. науч.-практ. конф. молодых ученых, посвященной 85-летию со дня рождения Р.Г. Кузеева. - Уфа : ИЭИ УНЦ РАН, 2014. - С. 92-95.

10. Султанова, А. Н. Бирский могильник: историко-археологическая характеристика : дис. ... канд. ист. наук / Султанова Альфия Ниязовна. - Уфа, 2000. $203 \mathrm{c}$.

11. Сунгатов, Ф. А. Бронзовая фигурка всадника с Южного Урала / Ф. А. Сунгатов, Р. М. Юсупов
// Южный Урал и сопредельные территории в скифосарматское время. - Уфа : Гилем, 2006. -С. 246-256.

12. Тамимдарова, Р. Р. Бусы Бирского могильника из фондов археологической лаборатории Башкирского государственного университета / Р. Р. Тамимдарова // Материалы XLI Международной Урало-Поволжской археологической конференции студентов и молодых ученых. - Уфа : РИЦ БашГУ, 2009. - С. 320-324.

13. Тамимдарова, Р. Р. Этапы и характер поступления бус в Уфимско-Бельское междуречье в эпоху средневековья / Р. Р. Тамимдарова // Материалы $\mathrm{V}$ Башкирской археологической конференции студентов и молодых ученых (15 дек. 2012 г., г. Уфа). - Уфа : РИЦБашГУ, 2012.-С. 114-119.

\section{REFERENCES}

1. Ambroz A.K. Birskiy mogilnik i problemy khronologii Priuralya v IV-VII vv. [Birsk Burial Ground and the Problems of Chronology of the Urals in the 4th7th Centuries]. Srednevekovye drevnosti evraziyskikh stepey [Medieval Antiquities of the Eurasian Steppes]. Moscow, Nauka Publ., 1980, pp. 1-56.

2. Kovalevskaya V.B. Bashkiriya i evraziyskie stepi IV-IX vv. (po materialam poyasnykh naborov) [Bashkiria and Eurasian Steppe of the 4th-9th Centuries (Based on the Belt Sets)]. Problemy arkheologii $i$ drevney istorii ugrov [Problems of Archaeology and Ancient History of Ugric Peoples]. Moscow, Nauka Publ., 1972, pp. 95-118.

3. Mazhitov N.A. Bakhmutinskaya kultura [Bakhmutian Culture]. Moscow, Nauka Publ., 1968. 161 p.

4. Mazhitov N.A. Kompleksy s monetami VIIIv. iz Birskogo mogilnika [Complexes of the 8th Century With Coins From the Birsk Burial Ground]. Sovetskaya arkheologiya [Soviet Archaeology]. Moscow, Nauka Publ., 1990, no. 1, pp. 261-266.

5. Ostanina T.I. Naselenie Srednego Prikamya $v$ $I I I-V v v$. [The Population of the Middle Kama Region in the 3rd-5th Centuries]. Izhevsk, Udmurtskiy institut istorii, yazyka i literatury UrO RAN, 1997. 327 p.

6. Ruslanova (Tamimdarova) R.R. Busykhronomarkery mogilnikov Ufimsko-Belskogo mezhdurechya III-VIII vv. [Beads as Chronomarkers in Burials of Ufa-Belsk Interstream Area of the 3rd-8th Centuries]. Vestnik Samarskogo gosudarstvennogo universiteta, 2013, no. 8/1 (109), pp. 170-174.

7. Ruslanova R.R. Klassifikatsiya bus rannesrednevekovykh mogilnikov Yuzhnogo Priuralya [Classification of Beads From Early Medieval Burial Grounds of the Southern Urals]. Trudy IV $(X X)$ Vserossiyskogo arkheologicheskogo syezda $v$ Kazani. Tom II [Proceedings of the 4th (XX) AllRussian Archaeological Congress in Kazan. Vol. II]. Kazan, Otechestvo Publ., 2014, pp. 403-405. 
8. Ruslanova (Tamimdarova) R.R. Osobennost businnykh naborov Yugomashevskogo mogilnika [The Peculiarity of Bead Sets of Yugomashevo Burial Ground]. Innovatsionnyy potentsial molodezhnoy nauki: Materialy vserossiyskoy nauchnoy konferentsii 8 noyabrya 2013 goda [Innovation Potential of Youth Science: Proceedings of the AllRussia Scientific Conference, November 8, 2013]. Ufa, Izd-vo BGPU, 2013, pp. 236-240.

9. Ruslanova R.R. Puti i kharakter vzaimodeystviya naseleniya lesostepnogo Priuralya v epokhu rannego srednevekovya (po materialam bus Ufimsko-Belskogo mezhdurechya) [The Ways and Character of Cooperation of the Forest-Steppe Urals Population in the Epoch of Early Middle Ages (on the Materials of Beads of the UfaBelsk Interstream Area)]. Etnosy $i$ kultury UraloPovolzhya: istoriya i sovremennost: materialy VIII Vserossiyskoy nauchno-prakticheskoy konferentsii molodykh uchenykh, posvyashchennoy 85-letiyu so dnya rozhdeniya R.G. Kuzeeva [Ethnicities and Cultures of the Ural-Volga Region: History and the Present: Proceedings of the 8th All-Russian Scientific and Practical Conference of Young Scientists Dedicated to the 85th Birth Anniversary of R.G. Kuzeev]. Ufa, IEI UNTs RAN, 2014,pp. 92-95.

10. Sultanova A.N. Birskiy mogilnik: istorikoarkheologicheskaya kharakteristika: dis. ... kand. ist. nauk [Birsk Burial Mound: Historical and Archaeological Characteristics: Cand. hist. sci. diss.]. Ufa, 2000. 203 p.
11. Sungatov F.A., Yusupov R.M. Bronzovaya figurka vsadnika s Yuzhnogo Urala [The Bronze Figure of a Rider From the Southern Urals]. Yuzhnyy Ural $i$ sopredelnye territorii $v$ skifo-sarmatskoe vremya [The Southern Urals and Adjacent Territories in the Scythian and Sarmatian Time]. Ufa, Gilem Publ., 2006, pp. 246-256.

12. Tamimdarova R.R. Busy Birskogo mogilnika iz fondov arkheologicheskoy laboratorii Bashkirskogo gosudarstvennogo universiteta [The Beads of the Birsk Burial Mound From the Funds of Archaeological Laboratory of the Bashkir State University]. XLI Mezhdunarodnaya Uralo-Povolzhskaya arkheologicheskaya konferentsiya studentov $i$ molodykh uchenykh: Materialy konferentsii [XLV International Ural-Volga Archaeological Conference of Students and Young Scientists: Conference Proceedings]. Ufa, RITs BashGUPubl., 2009, pp. 320-324.

13. Tamimdarova R.R. Etapy i kharakter postupleniya bus v Ufimsko-Belskoe mezhdurechye $\mathrm{v}$ ehpohu srednevekovyya [The Stages and Character of Baeads Supply to the Ufa-Belsk Interstream Area in the Middle Ages]. V Bashkirskaya arkheologicheskaya konferentsiya studentov $i$ molodykh uchenykh: Materialy regionalnoy nauchnoy konferentsii studentov i molodykh uchenkh. BashGU, 15 dekabrya 2012 g., g. Ufa [5th Bashkir Archaeological Conference of Students and Young Scientists: Proceedings of Regional Scientific Conference of Students and Young Scientists, Bashkir State University, December 15, 2012, Ufa]. Ufa, RITs BashGU Publ., 2012, pp. 114-119. 